\title{
Implementation of Voice based Touchless Lift System
}

\author{
B. Swathi, Akshay S Prathap, Aiswarya V Kumar, Ranjitha R, Raviteja Kaki \\ Information Science and Engineering, New Horizon College of Engineering, Bengaluru, Karnataka, India
}

\begin{abstract}
Article Info

Volume 7, Issue 4

Page Number: 241-246

Publication Issue :

July-August-2021

\section{Article History}

Accepted : 10 July 2021

Published : 18 July 2021

In this rapid world of technology where voice begins its era of domination to replace the touch screens from smart phones to huge computer systems, bringing voice in day to day affairs becomes significant. An elevator or lift is a transport vehicle that moves people or goods from on floor to another floor in a building. Typically push buttons were used to send requests to the elevators. In recent times touch buttons are coming to use. But now voice recognition can replace the push/touch technology. Elevators being one such system used in daily life serves this purpose of making future generations hands free which also becomes a boon for the disabled as well as helps during the pandemic situation to avoid physical contact. The main objective of this project is to propose and assemble a voice operated lift/elevator control system. The proposed system acts as humanmachine communication system. This research combines electronic control technology with speech recognition technology. The input to the system is human speech. Speech recognition is the method of recognizing the vocal words to take the essential actions accordingly. This device is very helpful for paralysis, short height people and physically challenged persons.

Keywords: Speech Recognition technology, Human communication system, Arduino Mega, control system
\end{abstract}

\section{INTRODUCTION}

Someone who does not have complete body organs do not have both hands in particular will have problems if he uses the existing elevator system as it is today. The person must push buttons for a destination floor number or keypads are available at the lift panel room. Based on the author's idea of how we can make an elevator system with voice control, point by way of stating the number of floors in the heading so that the elevator can lead people to the floor on the go.

\section{LITERATURE SURVEY}

This system [1] proposed the layout of elevators that may be useful for individuals with disabilities, particularly elevators managed via way of means of voice.

Disability is a person who does now no longer have a whole hand organ or hand organs however does now no longer characteristic properly, however the individual can nonetheless use voice to govern the elevator. The studies combines speech reputation generation with digital manage generation used to

Copyright: @ the author(s), publisher and licensee Technoscience Academy. This is an open-access article distributed under the terms of the Creative Commons Attribution Non-Commercial License, which permits unrestricted non-commercial use, 
make the elevator manage system that may be managed via way of means of voice. Speech Recognition is a gadget that features to transform spoken language into the enter records. The gadget enter is human speech. The gadget will perceive spoken phrases to enter records for manage system.

Control of this system calls for a easy phrase and may best apprehend a few phrases. These structures are typically extra correct and extra without problems skilled, however couldn't apprehend phrases which might be past vocabulary ever taught. This gadget makes use of a sensor tool sound which name Easy Voice Recognition for the schooling method and the minimal phrase reputation and for manage gadget the usage of Arduino Uno. The phrase may be skilled for a most of 32 phrases. The check consequences said all phrases may be identified as a command to govern the elevator.

Someone who does now no longer have a entire frame organs do now no longer have each palms specially could have troubles if he makes use of the prevailing elevator device as it's far today. The individual have to push buttons for a vacation spot ground wide variety or keypads are to be had on the raise panel room[2].

The human voice is the power of the Audio Frequency (AF), with a frequency variety from three hundred $\mathrm{Hz}$ to $3500 \mathrm{~Hz}$. The definition of a frequency of one $\mathrm{Hz}$ is one wave in line with 2nd and $1 \mathrm{kHz}$ is same to a thousand $\mathrm{Hz}$ or one thousand waves in line with 2nd.

This well known has been regarded because Alexander Graham Bell first transmit voice alerts over the strength cord [1,3]. If we talk right into a microphone linked to the oscilloscope, then at the oscilloscope display seems circuit electric powered wave audio.

Whatever we are saying it's miles composed of numerous dozen simple sounds referred to as phonemes.
This phoneme may be diagnosed later with the aid of using a laptop program.

Based at the author concept of ways we will make an elevator system with voice control, factor through manner of declaring the wide variety of flooring within side the heading in order that the elevator can lead humans to the ground at the go.

In order to decorate[3] the look at of the kinematics of any robotic arm, parameter layout is directed consistent with sure requirements for the robotics.And also its ahead and inverse kinematics are discussed.The DH conference Method is used to shape the kinematic equation of the ensuing structure. In addition, the Robotics equations are modeled in MATLAB to create a $3-\mathrm{d}$ visible simulation of the robotic arm.This robotic arm is used to expose the end result of the trajectory making plans algorithms. The simulation has detected the motion of every joint of the robotic arm, and examined the parameters.

As a result carrying out the predetermined intention that's drawing a sine wave on a writing board.

A voice recognition module[4] is an easy speaking recognition board where an equipment is controllers using your voice alone instead of manual controllers which are controlled by buttons.

A paper published by O. Katsuhiko suggests how he replaces a mouse with a voice-controlled module.

His Study is a combination of speech recognition and electronic technology and how using this can replace the mouse functionality using voice.

Speech recognition ids a module that converts spoken language into input data.

What the device does is it takes the voice of the users as input data and does its functionalities accordingly. The control of that equipment recognizes a particular word. voice recognition module can function well the same way mouse based controller can, with voice command from $1-10 \mathrm{~cm}$ away, where the duration is 
approximately between 5-10 seconds which has the capacity of 32 voices .

In this paper[5] we are given a glimpse of the current scenario of the speech emotion detection. For the improvement of the emotional recognition rate at single mode, the bimodal fusion based on speech and facial expression is proposed. A database has already been established for speech and facial expression. Far each emotion speech parameters are extracted and the PCA method is used to detect speech motion.

Then a bimodal emotion detection of fusing facial expression information is analyzed. The results have shown that emotion recognition rate with the presence of binomial fusion is about $6 \%$ higher than the normal recognition rate with only speech recognition feature.

This paper[6] by Jagan.M, Vinitha.N, Ananth.R focused on design and the construct of the voice operated lift control system. It acts as a human machine communication system. Speech is recognition is the process by which the spoken words are taken as inputs and actions are performed according to it. The device was made keeping in mind how helpful it will be paralyzed, short heighted people and physically challenged people. It provides a communication mechanism between the user and the microcontroller lift system. A Dc motor is used to activate the motion of the lift in upward and downward direction based on the voice commands given by the user which used MAT lab code for recognition of voice commands.

$\mathrm{C}$ instructions are embedded in the microcontroller programmers. The microcontroller communicates with both, input and output model.

The input module of the micro controller takes the voice instructions given by the user as input and the controller check $s$ whether the lift has to moved upward and downward and the distance it has to cover.

Incase there is a fault detection the power failure buzzer is used.
This paper [7]affords the layout of the low price voice reputation primarily based totally domestic automation machine for the bodily challenged human beings tormented by quadriplegia or paraplegia(who can't circulate their limbs however can talk and listen) to manage the diverse domestic home equipment and may actuate the mattress elevation simply via way of means of the voice instructions in step with their need.

The proposed machine includes a voice reputation module, Arduino uno microcontroller, relay circuit to and an adjustable mattress. The voice reputation module desires to be trained first earlier than it could be used to apprehend instructions. Upon a success reputation of voice command, the Arduino drives the corresponding load with the assist of the relay circuit. The adjustable mattress elevation may be set to the 3 distinct modesas according to the consumer consolation and need. The accuracy of voice reputation module is likewise measured in distinct conditions.

The experimental outcomes validate the features of the proposed machine. The outcomes display the machine can offer super assistant to the bodily challenged human beings with none $1 / 3$ person's assistances.

To explicit our mind, we speak with unique human beings in diverse approaches [8] easily. But, it's far tough for Low/High $(\mathrm{L} / \mathrm{H})$ syndrome human beings, blind human beings and paralyzed or bodily handicapped $(\mathrm{PH})$ human beings to bring what they think. The blind human beings face problems in writing tests even as $\mathrm{L} / \mathrm{H}$ syndrome or paralyzed or $\mathrm{PH}$ human beings sense extraordinarily tough to explicit their ideas. This assignment tool can offer answer over those issues. For fixing this problem, an ARM7 LPC2148 Microcontroller controls the functioning of speech-to- textual content module, keypads or buttons, flex sensors and textual contentto-speech modules. 
With the assist of those components, all the above issues may be eliminated in unmarried clever tool.

Using this clever tool, blind human beings can write his/her examination with out interpreter the use of speech-to-textual content module.

By urgent keypad, L/H syndrome human beings can explicit their fundamental mind the use of textual content-to-speech module.

And with the assist of flex sensors, paralyzed or $\mathrm{PH}$ human beings can bring their message.

\section{METHODS AND MATERIAL}

\subsection{The Human Voice}

Human voice is the energy of Audio Frequency (AF). The frequency of human voice ranges between $300 \mathrm{~Hz}$ to $3500 \mathrm{~Hz}$. Frequency of $1 \mathrm{~Hz}$ is one wave per second and the frequency of $1 \mathrm{KHz}$ is $1000 \mathrm{~Hz}$ or 1000 waves per second. These standards are known since Alexander Graham Bell First transmitted voice signals over the power cord.

\section{Arduino mega}

Arduino mega is a microcontroller board. It is based on ATmega2560. Arduino mega has 54 digital input/output pins. Out of these 54 pins, 14 can be used as PWM outputs. It has 16 analog inputs, 16 $\mathrm{MHz}$ crystal oscillator, 4 UARTS, power jack, an ICSP header, a rest button, and a USB connection. Arduino has everything to support a microcontroller. We have to simply connect it to a computer with a USB. We can also power it with a AC-DC adapter or a battery.

\section{Elechouse V3 Voice Recognition Module}

Elechouse is one of the most simple, compact and easy to control voice recognition module. We can use this module in two ways : one is by using the serial port or through the built-in GPIO pins. General Output pins on the board can generate different kinds of waves while the corresponding voice command is recognized.

The v3 board can store up to 80 voice commands each with a duration of 1500 milliseconds. Any sound can be trained to be a command. We have to train the voice recognition module[9] before recognizing any voice commands. All the voice commands are stored in one large group like a library10,11].

\section{USB to TTL converter}

The converter is a combination of two products: USB toRS232 adapter which utilizes the FTDI chipset and RS232 to 5V TTL converter. It can convert the full duplex USB port to a $5 \mathrm{~V}$ TTL signal in either direction. This unit is powered by the USB port. It requires no external power supply. IT eliminates the need for flow control by featuring data direction auto turnaround. It uses the latest FTDI chipset and is fully compatible with Linux, Windows 7 32/64, Windows 8 32/64,vista 32/64, server 2008, server 2008 R2, server 2003,Mac 98/9/X,CE,98Se.

\section{7 segment display}

7 segment display is used to display a decimal number. It is used it electronic watches, digital display panels, electronic meter and other devices that displays numeric data. It has 7 segments which are controlled individually to display the digits or letters. Some 7 segment displays may have an extra dot to represent a decimal point.

\section{Push button}

Push button switch is a type of switch, it consists of a simple air or electric mechanism to on or off something. Depending on model they can operate with momentary or latching action function. The push button is made of a strong durable material such as metal or plastic. 


\section{HC595 shift register}

74HC595 is a shift register that works on serial IN and parallel OUT protocol. The data is received serially from the microcontroller and sends out this data through the parallel pins. The output pins by 8 can be increased by using a single chip. More than 1 shift register can be connected in parallel.

\section{Stepper motor}

Stepper motors are nothing but DC motors which move in discrete steps. The have many coils which are organised in groups called "phases". The motor rotates one step at a time by energizing each phase in sequence. We can achieve very precise positioning and speed control by using a computer-controlled stepping.

\section{Servo Motor}

Servo motor is a liner or rotary actuator that is used for precise control of linear position or angular position, acceleration and velocity. Servo motor consist of suitable motor coupled to a sensor for a position feedback. Servomotors are used in various applications such as robotics, CNC machinery or automated manufacturing and so on.

\section{Motor driver A3967}

The motor driver A3967 is a complete microstepping motor driver with a built-in translator. It is designed to operate the bipolar stepper motor in full- , half-, quarter- and eighth-step modes with capability of 30 $\mathrm{V}$ and $750 \mathrm{~mA}$.

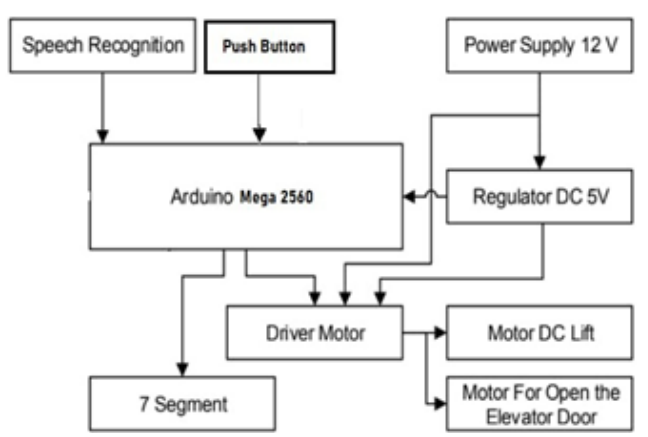

Figure 1. Block Diagram Simulator Controller Elevator
From the block diagram above, we are required to know the specifications of each sub-block diagrams in order to cooperate with each other. Next, we create a voltage or current source that is compatible with the hardware that we will use, with attention also needs at pin port to be used and are available from the microcontroller that we use.

\section{RESULTS AND DISCUSSION}

The measurement process is performed on the DC voltage parameters are out of the Power Supply. The first DC voltage measurements in the idle state (stand-by), and a second measurement in the active circuit conditions. Function 5volt DC voltage to energize the Microcontroller Arduino mega and entire block of pushbutton switches. Voltage DC 12 $\mathrm{V}$ is applied to the stepper motor and servo motor. The measurement results as follows:

\begin{tabular}{ccc}
\hline Object Measurements & \multicolumn{2}{c}{ DC Voltage } \\
& Stand by & Active \\
\hline Input Voltage & $225 \mathrm{Vac}$ & $225 \mathrm{Vac}$ \\
\hline Output +DC Voltage & $+13,7 \mathrm{Vdc}$ & $+12,4 \mathrm{Vdc}$ \\
\hline Output +DC Voltage & $+12,3 \mathrm{Vdc}$ & $+12,1 \mathrm{Vdc}$ \\
\hline Output +DC Voltage & $+5,2 \mathrm{Vdc}$ & $+5,1 \mathrm{Vdc}$ \\
\hline
\end{tabular}

Figure 2. The Output Voltage of The Power Supply when the Lift is active

The output voltage of the power supply when the lift is active will tend to decrease due to the increase in the load when the elevator is moving.

To test the software (program) has made the testing of the simulator elevator. Tests include elevator controller functions without using sensors and sound. The destination floor needs to be given as voice input and the 7-segment display shows the results 


\begin{tabular}{|c|c|c|c|}
\hline Floor & Floor Destintions & \multicolumn{2}{|c|}{ 7-Segnent Displey } \\
\hline Tislors & "rFloos & ${ }^{7 n}$ Fllow & suceed \\
\hline Int Flow & Int Flow & Int Flow & sumeed \\
\hline Trilar & ${ }^{46}$ Flas & ${ }^{4 t}$ Flors & sumeend \\
\hline "fiploos & "rislors & Irit Flor & slowerd \\
\hline${ }^{n \text { Fit }}$ Flos & ${ }^{19}$ Flor & "splos & suceed \\
\hline
\end{tabular}

Figure 2. Tests Elevator Controller Functions

Level 2 Level 1 Successfully Some People shout Due to the voice recognition is used in the form of modules so, then we assume to per- form the tests as above and compare it with the existing theory, the speech recognition technique with template-based approach. Voice recognition does not compare the sound module per syllable, or per phoneme, but per word. Matching technique using a template-based approach.

\section{CONCLUSION}

From the test results it can be concluded that the voice recognition techniques in voice recognition module with Arduino Uno as device control can work well to control elevators, with a memory capacity of 32 command depends on duration and intonation. The elevators will be useful for people with disabilities who do not have a complete limb or having limbs but does not function properly, but the person is still able to use his voice.

\section{REFERENCES}

[1] Lawrence Rabiner and Juang, Biing-Hwang. Fundamentals of Speech Recognition. United State: Prentice-Hall. 1993.

[2] Malvino, Albert Paul. Principles of Electronic Volume 2. New York: Salemba Teknika. 2004.

[3] M. Fugayama. Objects transfer robot arm control with Shape Similarity Using Kinematics Analysis. Thesis Program S1 Electrical Engineering University of Sam Ratulangi. Manado, 2011.

[4] O. Katsuhiko. Automatic Control Engineering (System Settings). Erland, Jakarta, 1998.
[5] PM Dwisnanto. Design of intelligent Robot Ants Using Microcontroller AVR ATMEGA 16 to determine the shortest track. Thesis S1 Electrical Engineering University of Sam Ratulangi. Manado, 2010.

[6] Guangming Xian, Biqing Zeng, Qiaoyun Yun, Xiongwen Pang. Non-Specific Person Continuous Speech Identification in Second Language using BPR. TELKOMNIKA Journal of Electrical Engineering. 2012;10 (7) : 1604-1609.

[7] Yutai Wang, Xinghai Yang, Jing Zou. Research of Emotion Recognition Based on Speech and Facial Expression. TELKOMNIKA Journal of Electrical Engineering. Vol.11, No.1, January 2013, pp. 83 $\sim 90$. 2013;11 (1) : 83-90.

[8] Jagan.M, Vinitha.N, Ananth.R.Voice Operated Intelligent Elevator. International Journal of Emerging Technology \& Research (IJETR). Volume 1, Issue 4, May-June, 2014.

[9] Mukesh Kumar, Shimi S.L. Voice Recognition Based Home Automation System for Paralyzed People. International Journal of Advanced Research in Electronics and Communication Engineering (IJARECE). Volume 4, Issue 10, October 2015.

[10] Pande Divyaprasad Digambarrao, M. Praveen Kumar. A Smart Device for People with Disabilities using ARM7. International Journal of Engineering Research \& Technology (IJERT). Vol. 3 Issue12, December2014.

[11] Prabhakar V. Mhadse, Amol C Wani Speaker Identification Based Automation System through Speech Recognition. International Journal of Emerging Technology and Advanced Engineering (IJETAE). Volume 3, Issue 1, January 2013).

\section{Cite this article as :}

B. Swathi, Akshay S Prathap, Aiswarya V Kumar, Ranjitha R, Raviteja Kaki, "Implementation of Voice based Touchless Lift System", International Journal of Scientific Research in Computer Science, Engineering and Information Technology (IJSRCSEIT), ISSN : 2456-3307, Volume 7 Issue 4, pp. 241-246, JulyAugust 2021. Available at doi : https://doi.org/10.32628/CSEIT217459 Journal URL : https://ijsrcseit.com/CSEIT217459 